\title{
Introduction to the Special Issue: Best Papers Presented at the OLC Accelerate Conference on Online Learning and the Innovate 2017 Conference
}

\author{
Anthony G. Picciano \\ City University of New York Graduate Center and Hunter College \\ Jill Buban \\ Online Learning Consortium \\ Laurie Dringus \\ Nova Southeastern University \\ Patsy Moskal \\ University of Central Florida
}

The Online Learning Consortium (OLC) is the leading professional organization devoted to advancing quality online learning, providing professional development for administrative leaders, support service individuals and faculty, and producing high-level research and best practice publications. OLC (formerly the Alfred P. Sloan Consortium) started in the 1990s when a small community came together to promote the idea that online learning could be of great benefit to providing access to a quality education. Funded by the Alfred P. Sloan Foundation, this community embarked on a number of activities designed to promote the concept that the design and implementation of online and blended learning applications needed to be well-planned and based on sound pedagogical approaches. In 1995, a one-day meeting of grantees of the Alfred P. Sloan Foundation's Anytime, Anyplace Learning Program met in Philadelphia to discuss their work and share their experiences. Ninety individuals attended this first gathering. This meeting grew into an annual event for the next five years. In 2001, it was decided that the event be expanded into a full conference with a formal, peer-reviewed call for proposals and workshops, and would include exhibit areas. The University of Central Florida agreed to host the conference in Orlando in November. That was a fateful decision as the attack on the World Trade Center on 9/11 followed by the anthrax scare in Florida in October of that year severely limited the number of people willing to fly to Orlando to attend the conference. Still, three hundred and sixty participants attended to share and discuss research, effective practices, student services, and administrative support for online learning. Since 2001, the conference has grown and has evolved into the premiere event for presenting current ideas, research, and best practices in online learning.

In 2016, the Online Learning Consortium celebrated the 22nd anniversary of the International Conference on Online Learning by giving it the new name of ACCELERATE. Over 2,000 individuals attended this conference either in person or virtually. Six hundred and seventysix proposals were submitted for presentation, of which 341 were accepted. 
In April 2017, the Online Learning Consortium held its second OLC INNOVATE Conference with 2,000 in-person or virtual attendees. Five hundred and forty-one individuals submitted presentation proposals, of which 282 were accepted. The nine articles selected for this special edition represent the best of the 623 papers accepted for presentation at these two venues, as determined by the conference track chairs and editorial staff of the Online Learning Journal.

\section{The Articles}

The nine articles in this special edition represent a wide variety of topics and issues worthy of research. The findings and conclusions add significantly to our understanding of online and blended learning. These articles also represent an excellent mix of research methods (quantitative, qualitative, and mixed-method). Doctoral students and others interested in research may find important insights into methodological techniques as used by the authors of these articles.

In Gap Analysis: An Innovative Look at Gateway Courses and Student Retention, William Bloemer, Scott Day and Karen Swan use examples from their work with the analyses of student records to show how one can use student type and point in their academic life to predict success in particular gateway courses. Relating predictions to observed Drop/Failure/ Withdrawal (DFW) rates can highlight courses exceeding expectations and those which fall below them, and support a more nuanced understanding of where attention is needed. They also look at whether or not actionable information can be found by looking at the general connection between DFW's and attrition for different groups of students in specific courses.

Janice Orcutt and Laurie Dringus in Beyond Being There: Practices that Establish Presence, Engage Students and Influence Intellectual Curiosity in a Structured Online Learning Environment, examine the decision processes employed in establishing teaching presence in a structured online environment in order to make a contribution to the body of knowledge from a practical pedagogical perspective. Using the lived experiences of instructors, this study focused on the exploration of the influence pedagogical choices had on the creation of an intellectual climate in the online context. Using semi-structured interviews as the main source of data, the study utilized the Interpretative Phenomenological Analysis (IPA) method as an analytical tool to address concerns of rigor in the qualitative interpretation of experiential data. Results of the collective case revealed student engagement and intellectual curiosity were influenced most greatly by an instructor's active interest and passion for teaching, an ability to identify the relevance of course topics to the student, and the encouragement for a shared responsibility in the learning process. The findings showed that the shared goal of learning extended beyond the stated learning objectives and expected outcomes of a course and served as a foundation in the creation of authentic relationships between instructor and students.

Jaclyn Krause, Laura Portalese, and Julie Bonner in Student Perceptions of the Use of Multimedia for Online Course Communication, explore student perceptions in taking both online and hybrid undergraduate project management courses. Specifically, the study sought to explore how students experienced the use of multimedia by their instructor and classmates in both online announcements and discussions, as well as whether these same students used or would be likely to use multimedia for similar communications. Student perceptions of social presence, the degree to which one is perceived as a real person in computer-mediated communication, were also examined. The results of the study indicate that while students overwhelmingly enjoyed the instructor's use of multimedia communication, they are unlikely to engage in using these technologies themselves. 
In Using Design-Based Research in Higher Education Innovation, Cristi Ford, Darragh McNally, and Kate Ford present the design-based research approach (DBR) used by the Center for Innovation in Learning and Student Success (CILSS) at the University of Maryland, University College. They provide details on one interpretation of DBR and how it can be applied by an innovation center working within a university for program evaluation. They posit that the conceptual framework and assumptions of andragogy (Knowles, 1984) have applicable relevance to the instructional shifts that include adaptive learning in the curriculum and believe them to be the central features of the evaluation approach of adaptive learning software. To illustrate the approach, they provided the example of a recent pilot that uses the adaptive learning software Realizeit in UMUC's Principles of Accounting I course.

Jason Rhode, Stephanie Richter, Peter Gowen, Tracy Miller, and Cameron Wills in Understanding Faculty Use of the Learning Management System, conducted a study at a large, research-intensive public university in the Midwest that has used the same LMS for 15 years. This study used system logs and database queries to examine how faculty used the LMS. The results identified the features that were used most frequently and how usage had changed over time. In addition, the study compared the usage data for face-to-face and online courses to determine if there are differences in LMS use due to course modality. Based on these findings, it is possible to better understand the role the LMS plays in higher education and online learning, to inform development of next generation learning systems and other innovative technologies.

In An Instructor Learning Analytics Implementation Model, Holly McKee developed and validated a model to guide instructors in the implementation of learning analytics (LA) tools. Using design and development research methods, an implementation model was constructed and validated internally. Themes emerged falling into the categories of adoption and caution with six themes falling under adoption including: LA as evidence, reaching out, frequency, early identification/intervention, self-reflection, and align LA with pedagogical intent; and three themes falling under the category of caution including: skepticism, fear of overdependence, and question of usefulness. The model should enhance instructors' use of learning analytics by enabling them to better take advantage of available technologies to support teaching and learning in online and blended learning environments.

In Blended Learning from Design to Evaluation: International Case Studies of EvidenceBased Practice, Norm Vaughan, Aline Reali, Stefan Stenbom, Marieta Jansen Van Vuuren, and David MacDonald, compare and contrast faculty development programs for blended learning in four different countries in order to understand the benefits, challenges, lessons learned, and recommendations from such initiatives. The benefits identified for faculty members were that they became more reflective of their teaching practice and began to make a role adjustment from being a content provider to a designer and facilitator of learning for students. The greatest challenge appeared to be a lack of common institutional definition and understanding of blended learning as well as a lack of time and resources to support faculty in the redesign of their courses. With regards to lessons learned, each program emphasized the need for all institutional stakeholders to be involved in supporting the initiative and that blended learning does not simply imply adding digital technologies to an existing face-to-face course. The key recommendation from this study is that a faculty development program for blended learning needs to be clearly aligned with the institution's vision and mission. 
Wendy Howard, Gino Perrotte, Minyoung Lee, and Jenna Frisone in A Formative Case Evaluation for the Design of an Online Delivery Model Providing Access to Study Abroad Activities, evaluate the effectiveness of an online delivery model for study abroad activities. Building upon the findings of an initial exploratory program using Adobe Connect web conferencing tools, this evaluative case study was the second in a series of design-based research studies intended to identify effective practices and develop recommendations to refine the model through an iterative evaluation process. Using the Online Learning Consortium's Quality Framework, each of the Five Pillars that support successful online learning (access, student satisfaction, faculty satisfaction, learning effectiveness, and scale) was evaluated through a combination of anonymous surveys, pre/post assessments, observations, and student and instructor interviews.

Last but not least, Laura Brewer, Holly Rick, and Karen A. Grondin in Improving Digital Library Experiences and Support with Online Research Guides, examines how the introduction of a Literature Review library guide influenced online business students' perceived value of the resource. A population of undergraduate business students $(\mathrm{N}=355)$ and online MBA students $(\mathrm{N}=319)$ were introduced to a Literature Review library guide during specific points in their programs. Students were asked to complete an online survey that included 17 closed-ended items designed to measure perceived usefulness, satisfaction and likeliness to use the guide again. The survey also included two open-ended questions asking students to discuss those elements of the guide they found most valuable and whether any features had not been included in the guide, but which they wish had been. The data collection strategy required faculty post information about the Literature Review library guide and the survey in their courses at two specified times in the course. Overall, students reported being satisfied with the resource and that they found it usable. Graduate students were more likely to report elements of the guide that supported effective search and evaluation strategies were valuable; undergraduate students tended to value the links to writing resources. Student feedback also suggested that the earlier the guide was introduced in the program, the more likely students would use the resource.

In closing, we would like to acknowledge the efforts of a number of individuals who made critical contributions to this special issue, particularly Sturdy Knight, Beth Meigs and the staff of the Online Learning journal(OLJ); Peter Shea, for his guidance as editor of OLJ; Kathy Ives, for her leadership and direction in navigating the Online Learning Consortium; and the OLC staff and program committees for their efforts and dedication in organizing the conferences at which the authors originally presented their research.

The editors of this special issue hope our readers enjoy the articles selected and welcome any comments. 